\title{
Duas Sátiras SOBRE a DescoberTa da América: Performance e Engajamento no Teatro de Dario Fo ${ }^{1}$
}

\section{Luís Felipe Ferrari \& Marcia Maria de Arruda Franco*}

RESUMO: Neste artigo tentamos analisar duas peças de Dario Fo que tratam da descoberta e da colonização da América: Isabella, Tre Caravelle e un Cacciaballe e Johan Padan a la Descoverta de le Americhe. Nosso objetivo é demonstrar que a comédia de Fo desenvolve uma articulação íntima entre performance e engajamento político, na medida em que a construção da cena se mostra dependente da crítica da sociedade e da história.

PALAVRAS-CHAVE: Dario Fo; Descoberta da América; teatralidade; engajamento político.

ABSTRACT: In questo articolo si cerca di analizzare due commedie di Dario Fo il cui tema è la scoperta e la colonizzazione dell'America: Isabella, Tre Caravelle e un Cacciaballe e Johan Padan a la Descoverta de le Americhe. Il nostro scopo è dimostrare che la commedia di Fo propone un' articolazione intima tra performance e impegno politico, poiché la composizione delle scene si mostra dipendente dalla critica della società e della storia.

PAROLE CHIAVE: Dario Fo; Scoperta dell'America; teatralità; impegno politico

ABSTRACT: In this article, we attempt to analyze Dario Fo's plays on the discovery and the colonization of America: Isabella, Tre Caravelle e un Cacciaballe e Johan Padan a la Descoverta de le Americhe. We intend to demonstrate that Fo's comedy advances an intimate connection between performance and political commitment, insomuch as the stage is perceived as dependent on a social and historical critique.

KEYWORDS: Dario Fo; Discovery of America; theatricality; political commitment.

\footnotetext{
${ }^{1}$ Esta publicação decorre de uma pesquisa de iniciação científica financiada pela Fundação de Amparo à Pesquisa do Estado de São Paulo, processo n. 2017/19766-4.

*Universidade de São Paulo (USP)

luis.ferrari@usp.br/mmaf@usp.br

http://dx.doi.org/10.11606/issn.2238-8281.v0i39p34-43
} 
á se notou, muitas vezes, como, apoiando-se no carnaval, na Commedia dell'Arte e no marxismo de linha gramsciana, Dario Fo fez da comédia uma força crítica, se não propriamente revolucionária, para rebelar-se contra toda sorte de estabelecimentos hegemônicos ${ }^{2}$. A performance cômica que Fo executa diante de seus espectadores - seria melhor dizer, desde já, na companhia de seu público - deve ser considerada, segundo vemos, a partir de três fatores: (1) o modo como é construída a teatralidade da cena; (2) a subversão do primado enunciativo da história que ela possibilita; e, por fim, (3) o papel privilegiado do corpo no desenvolvimento da narrativa. Mas, se assim procedermos, não tardaremos a perceber que uma unidade inextrincável reúne esses fatores. Trataremos dessas questões aqui de modo circunstancial, pois não olhamos o conjunto espantoso da obra de Fo, mas duas de suas peças que, embora não sejam de modo algum capazes de fornecer uma impressão satisfatória da versatilidade de seu teatro, podem muito bem nos oferecer um ponto privilegiado para tratar de sua poética. Nós abordaremos aqui duas peças de Fo acerca do descobrimento do Novo Mundo: Isabella, Tre Caravelle e un Cacciaballe e Johan Padan a la Descoverta de le Americhe ${ }^{3}$.

Seria conveniente as reunirmos, para que extraíssemos delas todo o sentido da crítica de Fo à conquista da América, se ele próprio, na verdade, já não o tivesse feito. Retornaremos a esse ponto adiante, quando discutirmos o prólogo de Johan Padan. Por hora, convém recordarmos um texto clássico, e não menos polêmico do que celebrado, de Diderot. Em "Paradoxo sobre o Comediante", o enciclopedista observa que o grande ator, como "a alma de um grande manequim" (DIDEROT, 2000, p. 34), não deve vivenciar a cena que representa, mas possuir total controle sobre sua performance a fim de provocar os efeitos pretendidos sobre o público. Entretanto, do mesmo modo como reconhecemos um aspecto de consciência no ator, devemos considerar que o sucesso da representação cômica exige igualmente a consciência do público. Isso pode ser compreendido rapidamente se tomarmos, por exemplo, no Brasil, as costumeiras "pegadinhas". A vítima, inocente da armadilha em que caiu, se exaspera e não vê nenhuma graça. Aquele que assiste, porém, ciente de que tudo não passa de um truque, ri justamente do fato que um dos envolvidos não sabe que se tornou parte de uma encenação.

Podemos concordar, então, com Josette Féral (2002) quando nota que a intencionalidade é vital para a emergência da teatralidade. Féral entende o teatro como uma prática de "ressemiotização" que preenche de um significado ficcional o espaço cotidiano e o gesto casual.

2 Uma apresentação ao estilo de Fo e uma introdução a alguma de suas peças mais notáveis pode ser encontrada em: Jenkins, R., 1986.

3 Agradecemos a Júlio Adrião, que gentilmente nos cedeu o texto de sua adaptação de Johan Padan para o português. 
Trata-se de admitir que a teatralidade tem suas origens não na instituição do teatro nem na natureza própria do objeto artístico, mas nas estruturas da vivência subjetiva. Isso, com efeito, nos obriga a reconhecer que nenhuma concepção de signo pode esgotar a funcionalidade do teatro; antes, devemos tratar de um processo contínuo de criação da realidade representada, tornado possível por uma experiência radical de alteridade - e isso não precisa depender de uma elaborada narrativa ficcional, dos códigos estritos de Voltaire ou dos ainda muito mais estritos do teatro nô, mas inclui desde happenings à mímica mais simples. Se dermos a devida atenção à concepção de poesia asserida por Valéry ${ }^{4}$, não ficaremos receosos em aventar uma generalização desse fenômeno.

Tudo se passa entre o público e a cena e entre o público e o ator. Seu corpo, suas falas e seus gestos atualizam a realidade ficcional de tal modo que, sugere Féral, dispondo da cumplicidade de sua audiência, ele pode dispensar-se de toda sorte de aparelhagem cênica. É o caso de Johan Padan. A cena é entendida como uma experiência na qual não só o espaço, mas especialmente o ator, corporal e dialogicamente, tornam-se outros, são vividos por nós como outros de quem são, sempre dentro do alcance de nosso reconhecimento. No limite - e Fo não deixou de tematizá-lo justamente sob a forma da censura ${ }^{5}$-, as fronteiras entre a espontaneidade e o criado, entre o próprio e o representado, são perdidas completamente. Nesse sentido, o teatro pode ser entendido como um espaço de compromisso mútuo, em que se aceita a existência e a experiência do outro sobre o espaço do real e da máscara/personagem ou "máscara" no sentido que Fo lhe atribui sobre o corpo. Aqui já estamos nos distanciando do texto de Féral, mas convém retornar a ele em mais um passo:

The actor is simultaneously the producer of theatricality and the channel through which it passes. He encodes it, and inscribes it with signs within symbolic structures on stage that are informed by his subjective impulses and desires. As a subject in process, the actor explores the 'other' he creates, making it speak. These perfectly encoded symbolic structures are easily recognized by a public that appropriates them as a mode of knowledge and experience. All are forms of narrative fiction (fantastical characters, acrobats, mechanized marionettes, monologues, dialogues, representations) that the actor brings to life upon the stage (FÉRAL, 2002, p. 100, grifo nosso).

Ora, o caso de Isabella é notável justamente porque inclui dentro de si o processo de criação do palco como um ambiente aceitável para a sátira. A peça a que assistimos é representada na Espanha por uma trupe de atores sobre um cadafalso - com direito até mesmo ao auxílio do algoz -, imediatamente antes que se cumpra a execução de um ator determinada pela Inquisição. "Esecuzione", é claro, recebe aqui seus dois sentidos: de performance cênica e de cumprimento da pena capital. Quando o ator anônimo se vê obrigado a executar uma última peça sobre o tablado da forca, o cadafalso transforma-se inesperadamente em um palco: Fo institui entre a peça e seu público um segundo palco e um segundo público. "E questo, perché si sappia che nel nostro paese ogni uomo sul patibolo può fare quel che gli pare: su questo palcoscenico non esiste censura" (FO, 2006, p. 7-8).

4 Cf. Paul Valéry, "Premier Leçon du Cours de Poétique”. Em: CEuvres, vol. 1. Editado por Jean Hytier. Paris: Éditions Gallimard, 1997.

5 "I don't know if you know this, but since many of our performances had been raided by the police, we decided to plant our own policemen led by a commissar - all imposters - who would interrupt the show. Some of our people would be carried off to the police station to be arrested... we provoked our audiences and there was always a great tension... people's anger was on the verge of exploding every minute. Some went so far as to pull out knives and assault the commissar". Cf. Ballerini et al., 1978, p. 39. 
É impressionante pensar como, nos últimos momentos antes de sua morte por heresia, este pobre ator recebe o direito de representar uma peça extremamente satírica à Coroa espanhola. Evidentemente, isso só é possível porque o ator será morto em seguida. A suspensão da censura ocorre em um espaço delimitado, que permite o questionamento do poder sem que ele seja verdadeiramente ameaçado por uma mudança real. Essa tensão, que estabelece no próprio palco os limites da ficção, é própria do que pretende a peça de Fo. O que assistimos é um exercício que pode afetar a realidade somente através da sensibilização do público. O seu teatro é, também aqui, uma tentativa de formar uma comunidade crítica e apelar a ela.

Compreenderemos melhor essa situação se nos apercebermos de que, em Isabella, tudo se passa durante o carnaval. Essa é a deixa para que Fo, com sua corporalidade irreverente e seus diálogos satíricos, subverta todo o aparato institucional da monarquia espanhola e os processos históricos envolvidos na descoberta da América. Na coincidência entre o palco real e o palco ficcional em que abre o espaço semiótico, Isabella vem mediada já de início por um contexto histórico e ideológico a partir do qual o ator pode - seguindo a palavra que foi proposta por Tunga para traduzir "performance" - desempenhar sua peça. O carnaval deve ser tomado, por isso, como um artifício composicional que viabiliza a sátira da história. A primeira cena de Isabella, predispondo o auditório a uma visão crítica acerca da história da Espanha, cumpre assim a função de estabelecer o ambiente de intencionalidade que torna a atuação possível. $\mathrm{Na}$ verdade, a simples presença das pessoas na audiência, que provavelmente já sabem quem é Dario Fo e conhecem a natureza de seu teatro, já contribui para isso antes mesmo da entrada em cena dos atores.

Como resultado, uma sociedade pecuniária, regida por interesses comerciais e por delírios religiosos pouco defensáveis, será oposta à imagem idealizada dos Reis Católicos. As viagens de Colombo, em especial, são destituídas da motivação evangelizadora e missionária com que eram então justificadas: elas não passam de um subterfúgio audacioso para recuperar os cofres de uma Espanha arruinada pelas Guerras de Reconquista (FO, 2006, p. 37-38). Fo dá força formal a essa ideia ao encenar em paralelo as batalhas contra os mouros - empreendidas por um emasculado e ignorante Rei Fernando - e as capitulações na corte, cruzando-as sobre o palco (FO, 2006, p. 28-30). O ator condenado tampouco se exime de denunciar as relações comerciais de Inocêncio VIII com os banqueiros genoveses (FO, 2006, p. 42) ou o fato de a expulsão dos judeus ter se devido ao oportunismo da Coroa, que não se eximiu de violentá-los para apossar-se de seus bens (FO, 2006, p. 43-44). Enfim, o próprio Colombo não é mais do que um dedicado embusteiro, um "cacciaballe" que se valerá de desavergonhados truques e artifícios para realizar sua lucrativa empreitada. Uma atrás da outa, as mentiras e trapaças de Colombo são reveladas ao longo do segundo ato. Bem o diz um coro de marinheiros, ao final do primeiro ato: 
Cristoforo Colombo con due facce di bronzo

cacciando qualche balla

ottenne le tre caravelle

e infine per l'India salpò.

Ma si sa che chi imbroglia, a sua volta è imbrogliato:

cercava le Indie e in America s'è trovato. (FO, 2006, p. 53)

Podemos voltar, agora, nossa atenção à segunda peça. Aqui, Fo tratará propriamente da colonização do Novo Mundo. Contudo, como afirma o próprio ator-performer, não se trata de um retrato merencório das catástrofes da conquista, mas, surpreendentemente, de "l'epopea di un popolo di indios vincenti" (FO, 2001 , p. IX). Ao contrário de Isabella, Johan Padan dispensa um grande elenco, necessitando apenas da incomparável habilidade para a pantomima e do domínio prosódico inigualável de Dario Fo. É um monólogo - ou, como prefere o autor, uma giullarata. Adotemos a concisa definição de Antonio Scuderi (2003, p. 277): "Based on various techniques of popular performance and oral traditions, the giullarata is essentially a story-telling event, whereby Fo alternates between narrating a tale and acting out the various parts". O caráter épico-pantomímico das giullarate traduz-se na exigência de que Fo desempenhe diversos papéis em sequência ou em simultâneo, alternando entre o discurso e a representação física. Especial neste caso, nota ainda, é Johan Padan, constituída por uma narrativa única e ininterrupta: a hilária e obscena aventura de um genovês que, para fugir da Inquisição, torna-se marinheiro em uma das viagens de Colombo à América, separa-se dos espanhóis, sobrevive aos canibais e lidera uma insurreição de índios contra os colonizadores, por fim assimilando-se à tribo e deixando para trás o velho continente.

Fo já não dispõe de acessórios cênicos nem de fantasias, usa-se apenas de seu corpo, vestindo tão-somente uma fina blusa negra. É o ator apenas, utilizando nada mais do que seu corpo, quem cria a teatralidade. Vemos que, para torná-lo possível, o prólogo é fundamental, pois ele cumpre o papel de dar autoconsciência à audiência, predispondo-a à recepção desejada. Ora, o prólogo de Johan Padan se inicia referindo a recepção polêmica de Isabella, Tre Caravelle e um Cacciaballe trinta anos antes. Em um primeiro momento, somos sensibilizados para a controvérsia própria do tema da peça, e, em seguida, Fo explica à audiência as fontes que usou para compô-la. Cabeza de Vaca, Hans Staden, El Inca Garcilaso, Gonzalo Guerrero, o primeiro mestiço das Américas - tal como sua história foi recontada por Geronimo de Aguilar -, e, recebendo um destaque especial, Michele da Cuneo, autor de uma carta a respeito da segunda viagem de Colombo, são os nomes que cita (FO, 2001, p. XII). É já interessante que Fo selecione esses documentos, desprezando os relatos do próprio Colombo ou as mais prestigiosas crônicas dos conquistadores e dos frades. Na verdade, ao fazê-lo, Fo seleciona textos que nos aproximam dos homens subalternos, dos tripulantes anônimos dos navios e dos índios massacrados nessa empreitada de reis e generais. Cuneo o ilustra exemplarmente. Opondo-se ao tom solene do Almirante, cujas missivas são endereçadas aos reis, Cuneo dirige- 
-se a um amigo em privado e narra sem nenhum pudor os assaltos perpetrados pelos navegantes ou o estupro de uma mulher indígena que ele próprio comete. No seu relato, o descobrimento é pouco mais que uma aventura insólita, motivada pela ganância e por uma curiosidade obscena.

Mas é preciso cuidado. Não é com rigor historiográfico que Fo se aproxima desses textos, mas com liberdade criativa, manipulando-os e por vezes inventando documentos à mercê de seu humor. Nos seus prólogos, muitas vezes assenta suas peças sobre a segurança historiográfica de manuscritos e fontes antigas, por vezes as relacionam com eventos transpassados recentemente, dando-nos a aparente convicção de que não faz mais do que encenar um fato verídico. Mas, na verdade, borraram-se completamente as distinções entre o fictício e o verdadeiro ${ }^{6}$. Suas referências a certos textos e meios de transmissão da tradição (a expressão torna-se um pleonasmo por força do trado latino) talvez estejam interessadas, principalmente, nas práticas de cultivo da história e da cultura, ora ressaltando o caráter folclórico, quando fazem menção a fábulas orais ouvidas de contadores de histórias, ora desconstruindo as narrativas hegemônicas pela força dos próprios documentos que as embasam. Tudo se passa, nesse caso, como um problema de enunciação, pois é menos a autoridade da história que Fo deseja para si do que a subversão das narrativas historiográficas que cristalizam os exercícios vigentes do poder. Ao revestir-se com o manto da oralidade, ao ressaltar textos marginais e manuscritos comprometedores reais ou não -, já aqui Fo executa um exercício sofisticado de carnavalização. Nesse caso, suas atitudes não devem ser tachadas de erros ou extravagâncias filológicas; de nada importa que sejam inexistentes os manuscritos que porventura evoca, pois é a imaginação crítica que atua para rebaixar um passado que, através de uma narrativa documental, foi erigido como presença opressora sobre o presente. Esse já era, evidentemente, o caso com Isabella.

Há, ainda, duas informações vitais que o prólogo nos confia. A primeira é a revelação de que o texto da peça não foi fixado. Fo baseará sua performance em desenhos feitos de próprio punho em um livro deixado sobre o palco. Toda a narrativa se desenvolverá, pois, como um improviso preparado. A segunda é que o relato de Cuneo, conforme nos diz Fo, foi redigido pelo navegante em uma linguagem compósita, misturando castelhano, genovês, savonês e vêneto, com elementos do árabe e do português. O texto de Johan Padan, inspirado em Cuneo, compõe-se, principalmente, de catalão, castelhano e lombardo (nos dialetos de Bréscia e de Bérgamo), inseridos no napolitano, ainda com um pouco de vêneto, provençal e português (FO, 2001, p. XII). Fo pretende que essa mélange dialetal possa recuperar a língua dos portos de Veneza nos Quinhentos (FO, 2001,p. 1). Aqui, a própria linguagem também atua.

Em todo caso, esse longo prólogo informa a audiência a respeito de tudo o que se passa na peça. Como se ainda não tivesse se consumado a perda de qualquer ilusão de naturalismo, do palco, que não é de modo algum um palco no sentido convencional do termo, Fo instrui tal e tal pessoa a se sentar mais perto e interrompe sua primeira fala como ator para ironizar a própria dificuldade de sua linguagem (FO, 2001, p. 1). À sua audiência, resta apenas entregar-se ao prazer mais ou menos árduo de ser carregada por Fo para outro tempo e lugar. Precisamos atentar ao conteúdo ideológico dessas mediações, pois Fo associa à força crítica própria do

6 Ver a esse respeito também a apurada opinião de C. Maeder em "Mistero buffo: Negating Textual Certainty, the Indivial, and Time”. Em: Scuderi, A. e Farrell, J. (Orgs.). Dario Fo: Stage, Text, and Tradition. Carbondale: SIU Press, 2000 . 
teatro épico a recuperação da práxis cultural do povo. O prólogo nos permite compreender a sua giullarata como um tensionamento político dos limites estruturais e culturais entre a voz e o texto. É interessante nos voltarmos a Paul Zumthor nesse ponto. Embora reconheçamos a sua contribuição para os estudos da poesia oral e da performance, devemos criticar Zumthor por eximir peremptoriamente a performance de qualquer aspecto político, mesmo quando reitera a operação constitutiva do tripé autor-obra-leitor no ato literário e performático ${ }^{7}$. No caso de Fo, o engajamento político torna-se não apenas uma obviedade inescapável, mas o próprio fundamento de sua prática teatral. Se, para Zumthor, a performance for rigorosamente a-histórica em seu apelo ao sensível, se for presente como apenas o momento vivo e imediato da recepção pode sê-lo, nós não deveríamos considerar, porém, que algo de eminentemente político poderia surgir na própria tessitura desse espaço poético, quando ocorre a transformação de um espaço cotidiano em um espaço teatral? E mais, não deveríamos considerar que, justamente por executar-se em um presente determinado e situado, os indivíduos envolvidos na performance carregariam consigo uma ontologia social? Enfim, que o processo performativo seria, ele mesmo, uma força política na sua relação com o espaço não-artístico?

Quanto à primeira questão, a resposta de Fo é evidente. Devemos lembrar que, na maior parte de sua carreira, Fo não se apresentou em teatros, mas em fábricas durante greves de operários, em praças públicas ou diante de cadeias onde se encarcerara um preso político. $\mathrm{O}$ palco é ali instituído mediante o reconhecimento por parte da audiência de um significado ideológico do espaço. Muito embora esse não seja o caso com Isabella ou Johan Padan, já sabemos que essa dimensão não se perde, mas é também desenvolvida na composição de seus espaços cênicos. Quanto a ambas as peças, é possível dizer que o próprio palco, no sentido mais simples do termo, não existiria sem o dado político.

Quanto à segunda indagação, devemos notar que o presente enunciativo com que a performance de Fo trabalha atualiza também um subtexto ideológico. Em geral, as peças de Fo tratam de teatralizar ora ocorrências jornalísticas recentes, expondo escândalos atuais ao reproche Morte Acidental de um Anarquista é um exemplo famoso -, ora de retirar da história momentos típicos e significativos para a autoridade que neles se imbui e que se deseja atacar. Nesse presente, opondo-se ao voyeurismo do teatro naturalista, devemos reconhecer que a performance ciência traz para dentro de si um outro, diante do qual a audiência é uma parte interessada, já que detém uma opinião sobre, se não for diretamente afetada por ele. O próprio Fo atentou para este fato em uma entrevista:

[...] This means that the actor must be the exclusive renderer of whatever happens, that he does not have to wear a robe to become a character, but to become a mask. So, what is this mask? The mask is the dialectical synthesis of conflicts, whereas a character carries with him conflicts without ever achieving their synthesis. He thus tries to be himself, that is, to identify completely with his role and to recount his own trippe, as Molière said, the disturbances of his own self. So the actor is an individual entity, while the mask is collective, because it tells of a general concern.

7 Tomo por exemplo o trecho seguinte, parte de uma entrevista reproduzida em Performance, Recepção, Leitura: "Terceira: é evidente que não nego a existência de outros critérios de poeticidade, que têm a ver com a produção do discurso, desse discurso como tal, o texto ou o grupo social no qual ele funciona. Nesses planos intervêm fatores que designam os termos tradição, código ou (para tomar uma palavra já muito antiga, mas ainda utilizável com prudência) ideologia. Ora, esses fatos permanecem, em princípio, exteriores ao que visa a perspectiva que eu escolhi”. Cf. Zumthor, P., 2007, p. 25. 
In still other words, it is the voice of the story, not the means of acting it out. It is not I who identify with what I present onstage. Rather, I can criticize, suggest conflicts, contradictions, hypocrisies, and comment under any circumstance. This is the epic fact, the estrangement. The estrangement gives the actor the same possibilities that the puppets give the puppeteer. This is theater's fundamental ideological condition. And this is drama (BALLERINI et al., 1978, p. 43, grifo nosso).

Ora, não podemos dispensar-nos de reconhecer o fato de que é ideológica a divisão com que se força trabalhar, nas sociedades ocidentais, entre oralidade e escrita, uma vez que a segunda se tornou padrão distintivo da elite e a primeira foi relegada ao povo. Seu teatro executa-se como teatro, justamente pela recuperação de traços de uma cultura popular suprimida em seus dialetos e modos particulares de expressão pelas práticas culturais da elite. Mas o recurso a um outro socialmente constituído - que, via de regra, é o próprio povo, mas pode ser determinado como o operariado ou como os índios americanos - engendra toda uma nova linguagem. Ferozmente física em sua expressão, o corpo toma na peça de Fo quase todo o espaço do diálogo. A grande força dessa comédia se encontra na oralidade vigorosa que sobrepuja qualquer tentativa de fixação em um texto escrito, pois este se verá frequentemente forçado a deixar um espaço em branco ou longas reticências, demonstrando sua insuficiência diante do grammelot e das explosões sonoras das onomatopeias. A "máscara", no sentido em que fala Fo na citação precedente, é crida pela linguagem e pelo gesto. Ela indica ressemiotização do corpo do ator, em um processo mediado ideologicamente no qual podemos reconhecer o esforço de apropriação da cultura popular que se volta contra os desmandos do poder na história. Na oralidade insubmissa, o que se manifesta é uma deferência pelo povo e seus modos de vida negligenciados, pelos dialetos que não conhecem a ortografia e que foram expulsos das salas de aula pelo governo italiano.

Fo oferece seu corpo para tratar de questões coletivas e gerais. Todo o problema se põe, aqui, a partir da repressão da cultura e da opressão violenta dos povos indígenas. A fábula é desenvolvida pelas relações da personagem titular com os índios e dos índios com os colonizadores. Johan Padan é, em muitos sentidos, similar ao Colombo que acabamos de conhecer. Fo o descreve como um Ruzzante, a personagem campesina das peças de Angelo Beolco, ou como o ardiloso Zanni da Commedia dell'arte (FO, 2001, p. XI). Um registro farsesco acompanha a aventura deste italiano desgarrado, que fingirá ser capaz de prever tempestades, sobreviverá a um naufrágio amarrando-se a um porco - o que teria aprendido com Homero - e buscará constantemente deitar-se com as mulheres caribenhas. Ao cabo de um longo e ridículo périplo, Johan Padan, que viajou nas entranhas do navio envolvido pelas fezes dos porcos e das cabras que transportava, de modo assaz atrapalhado, ajuda os índios a expulsar da Flórida os colonizadores e os auxilia a defendê-la até que estes desistem de retornar.

Johan Padan se encerra com uma afirmação da mestiçagem. Johan permanece entre os indígenas, forma com uma índia uma família parte italiana e parte americana. Nestes termos, somos capazes de falar que a carnavalização, destruindo a opressão pelo riso, arrojou espaço para uma 
alternativa mais digna e alegre à colonização, na qual culmina, na verdade, todo o poder satírico da peça. O riso terá reescrito, aqui, a história, pois a fecunda imaginação cômica, exprimindo-se por práticas culturais emprestadas do povo, abriu caminho através de uma história violenta e cruel, alcançando a imagem fictícia de uma realidade mais humana. A ficção, apesar de não poder provocar alterações efetivas na organização do mundo, é uma arma crítica que pode se contrapor às instituições do poder. E, na medida em que for capaz de sensibilizar seus leitores e espectadores para outra forma de experimentar os problemas reais a que se refere, é de fato possível que venha a influenciar a realidade.

Convém remetermos essa nota de otimismo à cena final de Isabella. Aproximando-se do fim de sua encenação com a queda de Colombo à miséria e à doença, o ator enuncia sua última fala em tom de simpatia pelo marinheiro. Tendo feito de tudo para conquistar o seu quinhão, "non mi resta altro che tirare le conclusioni, non fosse altro che le conclusioni...". Mas o carrasco o interrompe: é a hora da morte (FO, 2006, p. 84-85). Não obstante, é agora o próprio ator que enuncia suas últimas palavras naquele palco onde tudo é verdadeiro, onde nenhuma lei, nenhuma autoridade tem direito a exercitar o seu poder:

Chi sta dalla parte del più potente

non sempre ha il vantaggio maggiore.

Se tu non sei prete non basta sembrare,

non basta in latino cantare.

Infatti il vero furbo è sempre l'uomo onesto,

non l'opportunista.

È l'uom che a tutti i costi

sta sempre e sol dalla parte

dei poveri cristi,

degli uomini giusti. (FO, 2001, p. 86)

A farsa, com todo seu poder invectivo e satírico, afana todas as prerrogativas e justificativas da opressão, encerrando-se com uma mensagem de solidariedade a todos os oprimidos. Mais: na verdade, aos "pobres cristos" que, como o Cristo morto na cruz pelos romanos, são fustigados pela Igreja e pelo Estado. Tomando em consideração o caráter metateatral dessa e, a rigor, de todas as suas peças, não parece inadequado fazer dessas palavras a profissão de fé do próprio Dario Fo. 


\section{Referências}

BALLERINI, L. et al. Dario Fo Explains: An Interview. In The Drama Review, Cambridge: 22 (1): 33-48, mar. de 1978. Disponível em: https://www.jstor.org/stable/1145166. Acesso em: 19/05/2019.

FÉRAL, J. Theatricality: The Specificity of Theatrical Language. Trad. Ronald P. Bermingham. In SubStance, Madison: 31 (2-3), 94-108, 2002. Disponível em: http://www.jstor.org/stable/3685480. Acesso em: 19/05/2019.

FO, D.; RAME, F. (ed.) Isabella, Tre Caravelle e un Cacciaballe. Milão: Fabbri Editori, 2006.

. Johan Padan and the Discovery of America (Edição bilíngue). Trad. Ron Jenkins. Nova York: Groove Press, 2001.

DIDEROT, D.; GUINSBURG, J. (org.). Diderot: Obras II - Estética, Poética e Contos. São Paulo: Editora Perspectiva, 2000.

JENKINS, R. Dario Fo: The Roar of the Clown. In The Drama Review, Cambridge: 30 (1): 171-179, 1986. Disponível em: https://www.jstor.org/stable/1145719. Acesso em: 19/05/2019.

SCUDERI, A. Unmasking the Holy Jester. In Theater Journal, Baltimore: 55 (2): 275-290, maio de 2003. Disponível em: https://www.jstor.org/stable/25069232. Acesso em: 19/05/2019.

ZUMTHOR, P. Performance, Recepção, Leitura. Trad. Jerusa Pires Ferreira e Suely Fenerich. $2^{\mathrm{a}}$ ed. São Paulo: Cosac Naify, 2007.

Recebido: 18/09/2019

Aprovado: 07/11/2019 